\author{
Cadernos de \\ ESTUDOS LINGUISTTICOS - (59.1), Campinas, pp. 53-71 - jan./abr. 2017
}

\title{
O LOCUS DA REFERÊNCIA NA LINGUÍSTICA COGNITIVA: REALISMO CORPORIFICADO, PROJEÇÕES CONCEPTUAIS E O DESAFIO DA INTERFACE DISCURSO-COGNIÇÃO
}

\author{
ROVE CHISHMAN* \\ ALINE NARDES DOS SANTOS ${ }^{* *}$
}

\begin{abstract}
RESUMO: Este ensaio objetiva mostrar como a Linguística Cognitiva tem redimensionado a discussão acerca da referência. Tal objetivo se desdobra nos seguintes: (i) situar os estudos de orientação cognitivista na discussão empreendida no âmbito da filosofia tradicional e (ii) refletir sobre a forma como as teorias cognitivistas têm lidado com o fenômeno por meio do princípio da projeção entre estruturas conceptuais estáveis ou locais/online. A partir dessas reflexões, ressalta-se que o paradigma da Linguística Cognitiva não apenas contribui para o debate filosófico acerca da referência, mas também para que se avance nas pesquisas que seguem o viés interacional-discursivo. Nesse ínterim, consideramos que a convergência entre abordagens linguístico-cognitivas e estudos discursivos é fundamental para que se se possa contemplar o caráter dinâmico e multifacetado do fenômeno da referência.
\end{abstract}

Palavras-chave: referência; Filosofia; Linguística Cognitiva; estruturas conceptuais.

\begin{abstract}
This essay aims at showing how Cognitive Linguistics has recontextualized discussions on reference. Such objective unfolds in the following ones: (i) to approach cognitivist studies concerning the issues raised in the context of traditional philosophy and (ii) to reflect on the way cognitive theories have dealt with this phenomenon by means of projection between steady or local conceptual structures. From these reflections, this essay considers that the Cognitive Linguistics paradigm not only contributes to philosophical debates about reference, but also to advances in research works identified with the interactional-discursive perspective. Therefore, it points out the convergence between cognitive-linguistic approaches and discursive studies is fundamental so that it can contemplate the dynamic and multifaceted character of the reference phenomenon.
\end{abstract}

Keywords: Reference; Philosophy; Cognitive Linguistics; Conceptual Structures.

\section{INTRODUÇÃO}

A questão da referência ou, em outros termos, do problema em saber como a língua refere o mundo, tem estado no cerne de discussões essenciais e controversas

*Universidade do Vale do Rio dos Sinos, Rio Grande do Sul (RS), Brasil. rove@unisinos.br

** Universidade do Vale do Rio dos Sinos, Rio Grande do Sul (RS), Brasil. aline.nardes@, gmail.com 
no âmbito da Linguística. Fazendo uma breve retrospectiva dos principais estudos em que tal temática tem sido tratada, é importante lembrar da chamada virada linguística, na primeira metade do século XX, período em que se evidenciou o impacto dos preceitos da filosofia da linguagem, em especial em sua vertente analítica, sobre as pesquisas linguísticas.

O problema da relação entre linguagem e realidade, ou da denotação e referência, passou a pertencer ao âmbito da filosofia; à linguística, em especial a de veio estruturalista, ficou reservado o tratamento da designação. Na esteira desse movimento, sobressaíram-se as abordagens lógico-analíticas e a própria fundação das semânticas vericondicionais, assim como das teorias formais. Essa visão, como bem expõe Marcuschi (2001), parte de uma postura epistemológica realista e considera a correspondência linguagem-mundo uma relação biunívoca e com uma significação rígida. A linguagem, sob tal ótica, tida como realidade mental, seria um espelhamento do mundo.

As teorias linguísticas contemporâneas que seguem tal perspectiva logicista, conforme se pretende destacar na primeira seção deste trabalho, operam no nível da sentença, mais especificamente as sentenças com conteúdo proposicional. Interessa a essa visão o estabelecimento das condições de verdade que dão inteligibilidade às frases.

Na contramão de tais abordagens, encontram-se as perspectivas teóricas que se apoiam na tese de que a referência não se dá apenas na relação linguagemmundo. Sob tal prisma, convergem as abordagens de inspiração interacional ou discursiva, assim como as de dimensão sociocognitiva com interesse em compreender como se dá o processamento da referência. Para esse segundo grupo, o interesse de pesquisa recai sobre o modo como estruturas conceptuais estáveis ou online e suas projeções - princípios que embasam o funcionamento da cognição humana (MIRANDA, 1999) - permitem-nos compreender processos de referência. São temas centrais para tais estudiosos os processos mentais como categorização, esquematização e projeções entre domínios (SALOMÃO, 2003).

É sobre esse segundo viés que pretendemos nos debruçar neste trabalho. Nosso principal objetivo consiste em mostrar como a Linguística Cognitiva (LC) tem redimensionado a discussão acerca da referência. Desdobramos tal objetivo em dois especificamente: (i) situar os estudos de orientação cognitivista na discussão empreendida no âmbito da filosofia tradicional e (ii) refletir sobre a forma como as teorias cognitivistas têm lidado com o fenômeno por meio do princípio da projeção entre estruturas conceptuais (frames, modelos cognitivos, espaços mentais), que podem ser agrupadas em estruturas de expectativa estáveis ou locais/online (TANNEN, 1979; TANNEN; WALLAT, 1985; MIRANDA, 1999; VEREZA, 2013a; 2013b).

Para atingir tais propósitos, dividimos este trabalho em quatro seções: a primeira situa a problemática no âmbito da tradição filosófica, dando ênfase à visão analítica sobre a referência; a segunda traz a visão de Lakoff e Johnson (1999) acerca das questões filosóficas. A terceira parte, por sua vez, reflete sobre as estruturas conceptuais estáveis que constituem o paradigma linguístico-cognitivo; já a quarta seção aborda a relevância das estruturas conceptuais locais no processo 
de referência, bem como a necessidade de uma abordagem sociocognitiva interdisciplinar do fenômeno, dado que esse processo envolve a articulação entre estruturas cognitivas estáveis e online. (VEREZA, 2013b).

A partir dessas reflexões, ressaltamos que o paradigma da LC não apenas contribui para o debate filosófico acerca da referência, mas também para que se avance nas pesquisas que seguem o viés interacional-discursivo. Nesse ínterim, consideramos que a convergência entre abordagens linguístico-cognitivas e estudos discursivos é fundamental para que se possa contemplar o caráter dinâmico e multifacetado do fenômeno da referência.

\section{A QUESTÃo da REFERÊNCIA NO ÂMbito dA TRADIÇÃo FILOSÓFICA}

Conforme já se destacou nas linhas introdutórias deste trabalho, a questão da referência nasceu no âmbito da filosofia da linguagem, mais precisamente no domínio da tradição analítica, vertente também conhecida como a Escola Analítica de Cambridge, cujos principais representantes são Frege, Russel, Carnap e Wittgenstein (representado pelo Tractatus logico-philosophicus) ${ }^{1}$. Os filósofos, a partir dos progressos da lógica no início do século XX, sentiramse motivados a recorrer aos estudos da linguagem como forma de solucionar problemas epistemológicos clássicos, como é o caso, por exemplo, das questões ontológicas. Segundo tal ótica, não há compreensão razoável para os problemas filosóficos que não passem por uma discussão acerca da linguagem. Marcondes $(2004$, p. 10) destaca que a filosofia analítica surge no terceiro grande período da tradição filosófica, o qual marca a ruptura da filosofia contemporânea com a filosofia moderna. É característico desse período a introdução da questão lógicolinguística, o que implica admitir que o conhecimento não pode ser compreendido independentemente de sua formulação e expressão em uma linguagem. É nesse contexto que emerge a concepção referencial do significado e o próprio foco nas sentenças com conteúdo proposicional. Dentre as indagações formuladas pelos filósofos analíticos, estão as que dizem respeito à maneira como palavras organizadas na forma de sentenças se vinculam à realidade. A inteligibilidade das frases, por sua vez, fica condicionada ao estabelecimento de condições de verdade. Em outras palavras, uma proposição é significativa se e somente se for possível estabelecer sua condição de verdade.

A fim de compreender melhor tal concepção, façamos menção a Frege, considerado um dos maiores lógicos do período contemporâneo e autor do importante artigo Sobre o sentido e a referência, cuja publicação, em 1892, marca o surgimento da vertente analítica da filosofia da linguagem. Coube a Frege a

${ }^{3}$ A segunda vertente da tradição analítica, também conhecida como Escola de Oxford ou filosofia da linguagem ordinária, tem em John Austin o filósofo mais representativo (MARCONDES, 2004, p. 36). 
introdução da ideia de que a tarefa filosófica de investigação do pensamento devesse ser feita como algo objetivo e atemporal, e não como algo psicológico e subjetivo (MARCONDES, 2004). É da autoria de Frege a conhecida distinção entre sentido (Sinn) e referência ou denotação (Bedeutung). A referência é o objeto designado, enquanto que o sentido é o modo de designar o objeto. O clássico exemplo do planeta Vênus, que também recebe as designações Estrela da Manhã e Estrela da Tarde, é reiteradamente citado para ilustrar a ideia de que um mesmo referente pode ter diferentes sentidos. Frege também introduz o conceito de representação.

O exemplo "O atual rei da França é calvo", apresentado por Russell ([1918] 1989), também é citado na literatura para ilustrar a dificuldade enfrentada pela semântica filosófica para sustentar que a estrutura do mundo e a da linguagem estão em relação de paralelismo. Nesse caso, como expõe Araújo (2004, p. 61), o problema reside na dificuldade em afirmar algo de um ser que não existe. Para Russell, a solução para esse caso reside em considerar a expressão denotativa "o atual rei da França" apenas como sujeito gramatical, e não como sujeito lógico. Trata-se de uma expressão que não serve para nomear, ainda que contribua para o sentido da sentença. Ao propor tal solução, Russell acredita estar reduzindo os compromissos ontológicos que se deva ter por razões semânticas.

Proposta similar foi apresentada por Wittgenstein no Tractatus. Araújo (2004, p. 74) chama a atenção para o desinteresse de Wittgenstein por uma abordagem psicológica acerca da significação. A análise da linguagem, sob a ótica do primeiro Wittgenstein, fica restrita às proposições que figuram os fatos em um espaço lógico, e o dizível limita-se às proposições com valor de verdade. Marcondes (2004, p. 40), por sua vez, aponta que é em seu último texto que Wittgenstein deixa claro que a proposta consiste em expressar em simbolismo apropriado aquilo que na linguagem ordinária gera infindáveis mal-entendidos.

Importa destacar que nãoé objetivo deste trabalho examinar de forma detalhada as diversas correntes teóricas da filosofia analítica e seus desdobramentos. Com essa breve digressão, importa compreender, outrossim, por que a relação entre linguagem e realidade, assim como problemas como a natureza da proposição, da referência e das formas de inferência válida, ocupam lugar central na vertente analítica da filosofia. O que preocupa os filósofos analíticos é a questão da fundamentação da ciência, o que implica considerar a lógica-matemática como sendo a solução básica. Com isso, a tarefa filosófica consiste essencialmente em resolver o problema epistemológico, pela busca de certeza e de objetividade alcançadas pelo confronto das representações mentais com relação ao mundo representado.

A análise da linguagem, nesse sentido, é vista como método filosófico, como procedimento através do qual a reflexão filosófica se desenvolve. Tendo clareza sobre esse ponto, o que fica evidente é que o principal propósito é produzir esclarecimentos, através da análise formal da linguagem, de problemas filosóficos, e não da natureza da linguagem propriamente dita. Em outras palavras, através da linguagem se chega à filosofia, e não o contrário. 
Ainda no âmbito da filosofia, convém fazer referência à mudança de enfoque proposta por Wittgenstein ([1957], 1979) e pelos expoentes da Escola de Oxford.

Wittgenstein, nas Investigações Filosóficas ${ }^{2}$, ao apresentar a noção de jogo de linguagem, assume uma concepção de linguagem bem distinta da assumida no Tractatus, o que o aproxima dos filósofos da Escola de Oxford, também conhecida como a vertente da filosofia da linguagem ordinária.

Importante aqui trazer as ponderações de Araújo (2004, p. 99) acerca do novo estatuto que a noção de referência passa a receber a partir do novo modelo proposto por Wittgenstein:

Pode-se afirmar que, até Wittgenstein II, a filosofia da linguagem baseava-se na proposição que retrata ou representa estados de coisa. A referência tem lugar central nessa perspectiva, que reduz a linguagem à sua capacidade unicamente assertórica. Mas, na medida em que a referência passa de questão CENTRAL a questão PERIFÉRICA, a própria noção de linguagem antes restrita ora às regras de um código, ora às formulações revestidas de valor de verdade, modifica-se, ampliando-se para os jogos de linguagem, com Wittgenstein e para os atos de fala, com Austin, Strawson e Searle (ARAÚJO, 2004, p. 99).

O excerto acima nos ajuda a compreender o caráter revolucionário presente no novo modelo. "Referir passa a ser apenas uma entre as inúmeras facetas da linguagem", complementa a autora. No lugar da linguagem cristalina moldada logicamente, Wittgenstein, apoiado na ideia de que a linguagem ordinária já está em ordem, propõe o conceito de jogos de linguagem, correspondendo a uma multiplicidade de usos, como prometer, descrever, sugerir etc. A referência, sob essa nova ótica, é um dentre os diversos jogos.

Conclui-se esta seção fazendo menção a Austin, filósofo da Escola de Oxford que também se recusou a pressupor o paralelismo entre linguagem e realidade como central. Considerado um dos pioneiros na crítica ao logicismo, Austin põe em xeque uma série de compromissos até então assumidos pela tradição filosófica. As afirmações deixam de ter um estatuto lógico privilegiado, como proposições assertóricas com valor de verdade, e passam a ser consideradas como atos de fala sujeitos a julgamentos de sucesso ou insucesso.

\section{O PROBLEMA DA REFERÊNCIA NO ÂMBITO DA LINGUÍSTICA COGNITIVA}

A fim de compreender de que forma os preceitos da filosofia analítica são redimensionados pela $\mathrm{LC}$, o que inclui repensar também o próprio estatuto da noção de referência, primeiramente é importante que se considere, conforme o fazem Lakoff e Johnson, in Philosophy in the Flesh, que há duas gerações de cientistas

4 Por Wittgeinstein apresentar pensamentos bem distintos nas obras Tractatus logicophilosophicus, de 1922, e Investigações Filosóficas, publicado postumamente em 1953, costuma-se referir ao autor como primeiro ou segundo Wittgeinstein ou Wittgeinstein I ou II. 
cognitivos: os de primeira geração, correspondendo aos seguidores de paradigmas que emergiram nos anos de 1950 e 1960 e que já nasceram comprometidos com a filosofia tradicional, e os de segunda, referindo-se às pesquisas que começaram a emergir do meio para o final dos anos de 1970 e que colocaram em xeque os preceitos assumidos pela primeira geração.

Incluem-se na primeira geração a inteligência artificial, a lógica formal e a linguística gerativa. Referindo-se a essa concepção como "a ciência cognitiva da mente desencarnada", Lakoff e Johnson (1999, p. 75-78) chamam a atenção para algumas características de tais paradigmas que evidenciam o seu compromisso com os princípios da filosofia analítica: (i) os significados são totalmente definidos a partir da relação interna entre os símbolos, (ii) os símbolos que caracterizam o pensamento são considerados representações internas de uma realidade externa, (iii) a mente é essencialmente desencarnada; (iv) as operações cognitivas são operações formais, (v) as categorias são definidas por condições necessárias e suficientes e (vi) o significado é literal.

A segunda geração, centralizando suas pesquisas na conceptualização e nos processos imagéticos como metáfora, metonímia, protótipos, frames, espaços mentais e categorias radiais, propõe o total abandono dos compromissos assumidos pela visão anterior. Segundo os autores, há três grandes descobertas das ciências cognitivas - a mente é corporificada; o pensamento é, em parte, inconsciente; e os conceitos abstratos são, em parte, metafóricos - que mostram a inconsistência de questões centrais da filosofia ocidental, o que aponta para a necessidade de revisão de parte da filosofia analítica anglo-americana.

Ao examinar de forma mais detida a primeira das três grandes descobertas apontadas por Lakoff e Johnson - a mente é corporificada -, é possível compreender não apenas a crítica que os autores fazem aos preceitos da filosofia analítica e indicação de revisão, assim como o contraste da LC em relação às teorias linguísticas que continuam se inspirando nos princípios filosóficos, tais como as semânticas formais e a teoria gerativa. A assunção de que a mente é corporificada implica rejeitar a visão de que há uma faculdade da razão que é independente da percepção, movimento, emoção e formas de interação no mundo. Por conseguinte, a realidade (e consequentemente a referência) não pode ser concebida independentemente de nosso compreensão, e as categorias deixam de ser concebidas com base em condições necessárias e suficientes, e sim com base na experiência.

A segunda e terceira descobertas reforçam o sentido alargado assumido pelo termo "cognitivo" no âmbito da Linguística Cognitiva, o que abrange quaisquer operações mentais e estruturas, conscientes ou inconscientes, que estão envolvidas na linguagem, percepção, sistemas conceptuais e razão.

A assunção de que os conceitos abstratos são, em parte, metafóricos, por sua vez, vem de encontro à visão de correspondência, objetivista, defendida pela filosofia analítica, assim como à concepção defendida pelos cognitivistas da chamada primeira geração de que a natureza da mente não se baseia em resultados empíricos. Não há significado metafórico ou imagético. Todo significado é literal, segundo os primeiros cognitivistas. 
Lakoff e Johnson (1999) defendem que a filosofia deve partir de uma ciência cognitiva empiricamente responsável, o que, em outras palavras, implica avaliar a adequação empírica dos argumentos filosóficos sobre conceitos, mente e linguagem e rejeitar suposições a priori. Fazendo um verdadeiro desmonte das bases epistemológicas da filosofia ocidental, os autores propõem o que chamam de Realismo Corporificado, concepção que parte da rejeição de dicotomias como racionalismo-empirismo e sujeito-objeto e confia no fato de que nós lidamos com o mundo através de nossas interações corporificadas. Tais postulados fundamentamse na primazia dos sistemas conceptuais humanos, cujas estruturas tornam-se o cerne das discussões sobre verdade e referência.

\section{REFERÊNCIA E ESTRUTURAS CONCEPTUAIS}

$\mathrm{Na}$ esteira das reflexões expostas na seção anterior, é possível pontuar que a visão experiencialista acarreta uma posição intermediária no que concerne ao processo de referência: rejeita-se o pressuposto objetivista de que, conforme ilustra Lakoff ([1987]1990), sistemas conceptuais humanos seriam como açougueiros, os quais simplesmente cortariam porções de carne da mesma carcaça - a realidade. No entanto, entendemos que a visão relativista, nesse contexto, não anula totalmente o objetivismo, dada a preocupação de Lakoff e Johnson ([1980]2003) em pontuar que é possível considerar a existência de um objetivismo a partir de uma noção diferente de realidade objetiva: essa realidade concerne a um sistema conceptual, condicionado a uma cultura, segundo o qual existem verdades corroboradas pelos membros da comunidade. Trata-se, portanto, de uma verdade "[...] relativa ao nosso sistema conceptual, o qual é ancorado e constantemente testado pelas nossas experiências e aquelas pertencentes a outros membros de nossa cultura em nossas interações diárias [...].” (LAKOFF; JOHNSON, [1980]2003, p. 193)³. Portanto, tratar de referência na Linguística Cognitiva pressupõe que consideremos as estruturas conceptuais que subjazem a esse processo.

Nesse sentido, o cerne da obra seminal Women, fire and dangerous things (LAKOFF [1987]1990), conforme abordado na seção anterior, consiste na tese de que "organizamos nosso conhecimento por meio de estruturas chamadas modelos cognitivos idealizados, ou MCIs", os quais refletem a teoria psicológica da categorização por meio de efeitos prototípicos (ROSCH, 1973). As noções de MCI, frame (FILLMORE, 1982; 1985) e domínios cognitivos (LANGACKER, 1987) são inter-relacionadas pelo próprio autor.

Visto que nosso objetivo não reside em elencar exaustivamente as distinções entre tais estruturas conceptuais - tal empreitada já foi realizada por autores como Cienki (2007) e Ziem (2014) -, interessa-nos abordá-las como conceitos que refletem "um tipo de estrutura de conhecimento que pode servir como pano de

5 “[...] relative to our conceptual system, which is grounded in, and constantly tested by, our experiences and those of other members of our culture in our daily interactions $[\ldots]$ ". 
fundo para se interpretar o significado de formas linguísticas." (CIENKI, 2007, p. 183$)^{4}$.

Nesse sentido, Tannen (1979) e Tannen e Wallat (1979) agrupam termos como frame, protótipo, esquema e script por meio do termo estrutura de expectativa: "baseado em sua experiência de mundo em determinada cultura (ou combinação de culturas), o sujeito organiza o conhecimento sobre o mundo e usa esse conhecimento para prever interpretações e relações referentes a novas informações, eventos e experiências." (TANNEN, 1979, p. 138-139)5. Como propõe a autora, as estruturas conceptuais propostas pelas abordagens linguístico-cognitivas também podem ser denominadas como estruturas de conhecimento, termo que remete às noções correspondentes advindas de abordagens computacionais pertencentes à segunda geração cognitiva.

A estruturação de frames por meio de slots e fillers, por exemplo, advém de estudos de Minsky (1974), no âmbito da inteligência artificial, o qual conceitua frame como uma situação estereotipada passível de ser representada computacionalmente a partir de nós e relações. Revisitando um exemplo do próprio Minsky, o termo festa de aniversário infantil pressupõe uma estrutura partilhada culturalmente, pressupondo slots como [decoração], [presente] e [comida]. Dizer que a festa tinha salgadinhos, por exemplo, ativa o slot [comida], cujo filler é [salgadinhos]. Fillmore (1976; 1977), apropriando-se do frame no contexto linguístico, complementa essas considerações, pontuando que outros slots podem ser ativados no curso da comunicação, visto que frames não necessariamente trazem todas as minúcias do evento: o processo de compreensão do falante, ao longo da inserção de um frame num ato de comunicação, inclui a busca de informações específicas ou mesmo o esclarecimento de dúvidas com seu interlocutor, conforme seu interesse ou necessidade (FILLMORE, 1976). Desse modo, o linguista, apesar de partir das considerações de Minsky em seu contexto computacional, busca ressaltar a dimensão cultural e comunicacional dos frames, compreendendo-os como categorias experienciais partilhadas por determinadas comunidades.

É a partir dos trabalhos seminais de Fillmore que Ziem (2014, p. 251) equivale a evocação ou ativação de um frame a um "ato cognitivo de referenciação" em uma área conceptual abarcada pelo frame. Desse modo, "Uma expressão se refere a uma unidade cognitiva ao evocar um frame, o qual então abre uma área de referência potencial". (ZIEM, 2014, p. 251) ${ }^{6}$. O frame, assim, pode ser entendido como área de projeção por meio das quais referenciamos entidades: a partir de um evocador de frame, o falante processa não apenas os slots materializados linguisticamente

6 " $[\ldots]$ a kind of knowledge structure which can serve as a background for interpreting the meaning of linguistic forms".

7 " $[\ldots]$ based on one's experience of the world in a given culture (or combination of cultures), one organizes knowledge about the world and uses this knowledge to predict interpretations and relationships regarding new information, events, and experiences."

8 "A linguistic expression refers to a cognitive unit by evoking a frame, which then opens a potential reference area. (ZIEM, 2014, p. 251). 
por determinados fillers, mas recorre a outras informações enciclopédicas que seu conhecimento de mundo permite apreender. A partir disso, ponderamos ser possível considerar que todas as estruturas de expectativa funcionam, em certa medida, como espaços de referenciação - os quais são "Estáveis, mas não estáticos", pois "qualquer estrutura de expectativa é dinâmica, uma vez que é continuamente confrontada com a experiência e revista." (MIRANDA, 1999, p. 82).

Ainda quanto ao funcionamento dos frames, um exemplo interessante para ilustrar a ativação dessas estruturas de conhecimento é dado por Ziem (2014), a partir de uma notícia veiculada no Chicago Tribune em 2004, traduzida a seguir:

Um passageiro japonês de 60 anos, em um voo partindo do Aeroporto Internacional de O'Hare, provocou uma suspeita de existência de bomba na última tarde de domingo, quando um passageiro o viu escrever as palavras "homem-bomba" em um pedaço de papel e alertou as autoridades, conforme declarou a polícia. Mas autoridades logo descobriram que o japonês, que estava viajando a negócios, estava apenas escrevendo palavras que não compreendia para poder procurá-las posteriormente em um dicionário [...]. O homem foi liberado, declarou a polícia, e autorizado a embarcar no voo, que partiu com três horas de atraso. (Chicago Tribune, 2 de agosto de 2004).

Como explica Ziem, esse exemplo pode ser descrito em termos de ativação (e não ativação) do frame de Terrorismo, por meio do termo homem-bomba principalmente se considerarmos que o evento ocorreu nos Estados Unidos, posteriormente ao episódio de 11 de setembro de 2001. Para o japonês, no entanto, a unidade não evocava frame algum, dado que o homem não tinha conhecimento da língua na qual a palavra estava escrita. Assim, embora estivesse em um local cuja temática terrorista é constantemente retomada, ele não pôde ativar a mesma estrutura conceptual evocada pelo outro passageiro em virtude de suas limitações linguísticas. Portanto, "De modo a compreender o significado de homem-bomba, o japonês teria de saber o frame ao qual a expressão se relaciona e acessar o respectivo conhecimento ancorado em sua experiência de mundo, que é prérequisito para que se compreenda tal expressão." (ZIEM, 2014, p. 6).

$\mathrm{O}$ exemplo é pertinente para mostrar que, segundo as teorias linguísticocognitivas, o processo de referência não pode ser compreendido sem que se levem em consideração a ativação de estruturas conceptuais relativamente estáveis, as quais são partilhadas por uma comunidade de falantes, cuja atividade mental e comunicativa (SALOMÃO, 2003) deve ser valorizada. No entanto, a atividade de ativação desses domínios também envolve instâncias mais locais da cognição (VEREZA, 2013b), que são cruciais para a compreensão da dimensão sociocognitiva da referência. É desse aspecto que trata a próxima seção.

\section{ENTRE O ESTÁVEL E O ONLINE: O DESAFIO DA INTERFACE COGNIÇÃO-DISCURSO}

Segundo a perspectiva da Linguística Cognitiva, sistemas conceptuais estáveis subjazem a processos de referência, considerando-se que, nessa perspectiva, a 
natureza desse ato de referenciar está diretamente ligada ao modo de funcionamento da cognição humana. No entanto, as chamadas estruturas de conhecimento estáveis não dão conta de descrever esse processo sociocognitivo. Tal dimensão online do fenômeno é foco da teoria dos espaços mentais (FAUCONNIER, 1985; 1994; 1997), categorizados por Miranda (1999) como domínios conceptuais locais (em oposição a estáveis). Segundo a autora, os espaços mentais

[...] são domínios dinâmicos, i.e., proliferam enquanto pensamos e falamos. Por isso são diferentes e novos a cada semiose. São produzidos como funções da expressão linguística que os suscita e do contexto que os configura. Externamente esses domínios estão ligados uns aos outros por conectores: marcas linguísticas e contextuais (Construtores de Espaços Mentais (CEM)). Internamente são estruturados por domínios estáveis. (MIRANDA, 1999, p. 86).

Para exemplificar o funcionamento dos espaços mentais, seguindo na temática do exemplo de frame na seção 4, vejamos a contrafactualidade presente na asserção de Chomsky (2013) a respeito dos Estados Unidos:

Eu coletei definições oficiais de terrorismo. [...] Coletei as definições dadas nas leis estadunidense e britânica [...]. Se você aplicá-las, verá que os Estados Unidos são um dos principais estados terroristas no mundo.

Tendo como foco a terceira parte do exemplo, temos a expressão "se você aplicá-las" como um Construtor de Espaço Mental contrafactual específico (C), a partir de um espaço de "realidade" (B), em que as leis antiterroristas são aplicadas aos Estados Unidos. Nesse caso, o país, no espaço mental de base, tem uma contraparte em (C), na qual é caracterizado como terrorista - fator que designa o chamado Princípio de Acesso, o qual estabelece que "uma expressão que nomeia ou descreve um elemento em um espaço mental pode ser usada para acessar a contraparte desse elemento em outro espaço mental". (FAUCONNIER, 1985, p. 4) ${ }^{7}$. Além disso, é necessário considerar que espaços mentais são sempre organizados internamente por meio de estruturas de conhecimento - nesse caso, podemos considerar, por exemplo, o Modelo Cognitivo Idealizado de Estados Unidos como vítima de ações terroristas, o próprio frame de terrorismo e o de aplicação de leis. A figura a seguir objetiva ilustrar essa dinâmica:

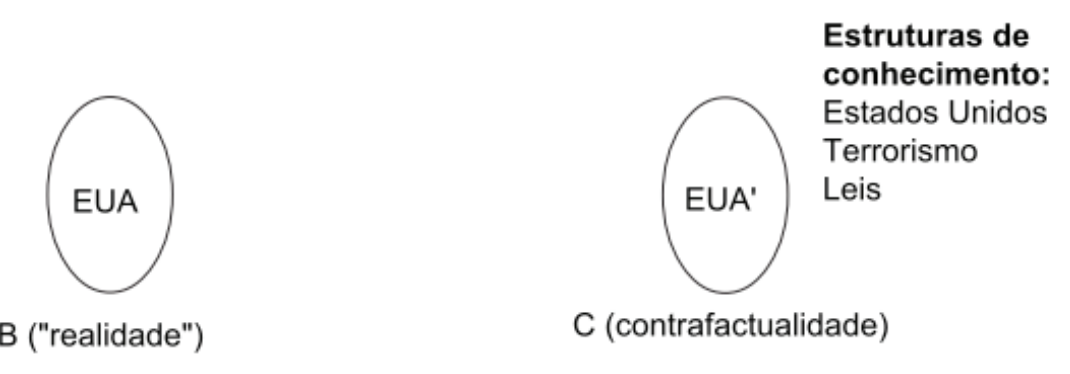

9 “' $[. .$.$] an expression which names or describes an element in one mental space can be used to$ access a counterpart of that element in another mental space." 
Esse exemplo simples mostra como "a teoria dos espaços mentais focaliza a dimensão cognitiva do desdobramento do discurso em planos epistêmicos" (SALOMÃO, 2003, p. 75). Dessa forma, a teoria não tem como pretensão explorar o funcionamento desse processo de referenciação em uma perspectiva mais discursiva, abarcando, por exemplo, questões de cunho interacional, argumentativo e ideológico. Ao encontro disso, Ziem (2014, p. 28) explica que teorias cognitivas como a dos espaços mentais têm como foco as "operações cognitivas que guiam a perspectivização de estruturas conceptuais" ${ }^{\text {. }}$. A partir dessa delimitação, questionamo-nos: ainda é possível sustentar tal restrição, em relação às questões discursivas, no estudo linguístico-cognitivo da referência?

Antes de tratarmos dessa questão, é interessante trazer a categorização de Vereza $(2010 ; 2013 b)$ quanto ao termo discurso, usada pela autora para fins operacionais. Nesse contexto, o estudo da referência a partir de estruturas de conhecimento estáveis estaria no nível do Discurso (com " $\mathrm{D}$ " maiúsculo), que compreenderia esse conjunto de experiências social e culturalmente partilhadas por uma comunidade. Já o discurso (com "d" minúsculo) abrangeria sua dimensão online - "o espaço onde os sentidos se produzem, reverberando o que já foi sócio e linguisticamente reiterado, e, ao mesmo tempo, revertendo, estendendo ou até mesmo desconstruindo essas reiterações, num jogo articulatório entre a cognição, a língua e o uso [...]" (VEREZA, 2010, p. 211).

Nesse contexto, as considerações de Salomão (2003), por exemplo, estabelecem uma separação entre as agendas de pesquisa discursiva e cognitiva, na qual cada área seria responsável por uma dessas dimensões discursivas:

As abordagens discursivas e cognitivas da referência convergem no reconhecimento da cena comunicativa como condição fundadora dos processos interpretativos: a divergência teórica entre elas se produz por uma diferenciação de ênfase nas respectivas agendas de pesquisa. Enquanto os estudos discursivos mais se guiam pelos aspectos sociais da gênese do sentido (a microfísica da interação, os gêneros textuais, as ordens ideológicas subjacentes), os estudos cognitivos têm preferido focalizar os processos mentais de categorização e esquematização, as projeções entre domínios epistêmicos, as transferências figurativas da estrutura conceptual, o gerenciamento do fluxo discursivo.

Considerações similares são encontradas em Lakoff (apud DIRVEN; POLZENHAGEN; WOLF, 2007, p. 37) ao tratar do lugar da ideologia nos estudos linguístico-cognitivos:

Ideologias têm aspectos conscientes e inconscientes. Se você pergunta a uma pessoa com uma ideologia política no que ela acredita, ela fornecerá uma lista de crenças e talvez algumas generalizações. Um linguista cognitivo, observando isso que ela diz, tenderá a detectar frames e metáforas inconscientes subjacentes à suas crenças conscientes. [...] É aí que linguistas cognitivos têm uma contribuição a fazer. ${ }^{9}$

10 "[...] the cognitive operations that guide the construal of conceptual structures."

11 "If you ask someone with a political ideology what she believes, she will give a list of beliefs and perhaps some generalisations. A cognitive linguist, looking at what she says, will most likely pick out unconscious frames and metaphors lying behind her conscious beliefs. To me, that is the interesting part of ideologies - the hidden, unconscious part. It is there that cognitive linguists have a contribution to make." 
Nesse ínterim, concordamos com Vereza (2010; 2013a; 2013b; 2016) quanto à necessidade de se ampliar perspectivas conceptuais em busca de uma convergência com a dimensão discursiva da linguagem. Como mostra a autora, diversos estudos ligados à metáfora ${ }^{10}$ já têm primado por essa aproximação, indicando que "o grande desafio dessa investida é conciliar cognição e discurso (linguagem em uso) e, principalmente, explorar a relação entre esses dois domínios, de modo algum dicotômicos, mas sim complementares." (VEREZA, 2016, p. 19-20).

A abertura para o discurso nos estudos de Vereza tem conjugado, às análises linguístico-cognitivas, aspectos discursivos diretamente relacionados a processos de referência, como a questão da argumentatividade e da deliberalidade, criticando a perspectiva de mera ativação ou evocação de representações cognitivas por parte dos falantes. Segundo a autora, é necessário considerar que as estruturas conceptuais, mesmo que estáveis, são constantemente e deliberativamente manipuladas pelos falantes conforme suas finalidades discursivas, de modo que não se trata de meras evocações, mas também de escolhas conscientes: "construir o objeto de discurso por meio de mapeamentos ou analogias ou até mesmo 'desconstruir' um provérbio [...] requerem uma postura metadiscursiva, que necessariamente se reveste de, pelo menos, algum grau de deliberalidade". (VEREZA, 2016, p. 25-26). Tais manipulações também permitem a análise da orientação argumentativa revelada a partir dessas escolhas - ou seja, a "orientação que as palavras dão ao discurso", as quais possuem uma "tendência para ser". (SILVA, 1998, p. 13).

Retomando o exemplo da frase de Chomsky, em termos referenciais, a teoria dos Espaços Mentais permite-nos compreender que o processo de referência se dá por meio da projeção de um espaço factual para um espaço contrafactual, por meio do qual se caracteriza os Estados Unidos como terrorista. Nesse contexto, abordar a dimensão deliberativa dessa projeção possibilita que consideremos os efeitos argumentativos dessa escolha. Por exemplo, é interessante observar que o Construtor do Espaço Mental contrafactual indica uma medida que seria esperada no espaço factual - o cumprimento das leis. Tal estrutura, nesse ponto, difere-se dos exemplos contrafactuais mais criativos fornecidos por Fauconnier e Turner (2002, p. 225), como "Na França, Watergate não teria prejudicado Nixon", relacionando espaços puramente hipotéticos. Nesse processo consciente de "realçar e encobrir" (VEREZA, 2016, p. 32), percebemos que a construção desse espaço mental contrafactual por meio da respectiva estrutura condicional coloca em evidência $o$ efeito argumentativo da criação desse espaço: se as leis foram criadas para serem cumpridas, e se as leis antiterrorismo condenam os Estados Unidos, por que sua condenação é apresentada como mera hipótese?

É em virtude da desconsideração desses aspectos que os trabalhos seminais relativos à teoria de Fauconnier são criticados por autores como Oakley e Hougaard (2008): para eles, os exemplos curtos e isolados que corroboram a descrição da teoria, embora sejam pertinentes, acabam por deixar em segundo plano os fatores contextuais e situacionais que permeiam a ativação e a manipulação de espaços

\footnotetext{
${ }^{12}$ Por exemplo, Cameron e Maslen (2010) Semino (2008) e Moura, Vereza e Espíndola (2013).
} 
mentais. Ao encontro do posicionamento de Vereza, os autores defendem que é necessário que a Teoria dos Espaços Mentais - e a Linguística Cognitiva como um todo - busque abranger cada vez mais a dimensão social do significado:

Muitos linguistas talvez considerem esse assunto como algo que extrapola o foco da própria Linguística Cognitiva, como se fosse uma preocupação sociológica e não linguística. Mas, na verdade, a Linguística Cognitiva em geral, e a Teoria dos Espaços Mentais e das Mesclagens Conceptuais em particular ${ }^{11}$, estão começando a abordar explicitamente a questão do significado socialmente construído e partilhado. (OAKLEY; HOUGAARD, 2008, p. 2). ${ }^{12}$

Nesse ínterim, é importante apontar a contribuição de estudos contemporâneos que valorizam o papel das teorias da Linguística Cognitiva no estudo da ideologia (KOLLER, 2014; HART, 2015; SEGUNDO, 2014), os quais permitem que associemos o processo sociocognitivo da referência à dimensão deliberativa do significado. Segundo essas abordagens, a integração entre modelos conceptuais linguístico-cognitivos e abordagens discursivas da ideologia permite que se perspectivize o fenômeno como conjunto de crenças que ativam, manipulam e convencionalizam estruturas conceptuais por meio da linguagem. Por exemplo, os estudos de Hart (2015) mostram como operações de conceptualização, incluindo a ativação de frames, constituem-se como ferramentas analíticas pertinentes ao campo da Análise Crítica dos Discursos, visto que esses processos cognitivos, evidenciados linguisticamente, possuem função ideológica e, portanto, permitem que se analise o posicionamento dos falantes, no que se refere a relações de poder que assegurem ou confrontem perspectivas opressoras de significado. (SEGUNDO, 2014). Em vista disso, podemos afirmar que tais estudos vêm propiciando avanços significativos no que se refere, especificamente, às convergências entre a Linguística Cognitiva e a Análise do Discurso em sua perspectiva crítica.

Ainda levando em conta os aspectos deliberativos e ideológicos do processo cognitivos de referência, é imprescindível mencionarmos os avanços dos estudos de referenciação, no campo da Linguística Textual (KOCH; MARCUSCHI, 1998; MONDADA; DUBOIS, 2003; CAVALCANTE, 2011, entre outros). Essa perspectiva defende que a referenciação é um ato cognitivo-discursivo de construção de objetos de discurso. Assim, considera-se que "nem os elementos do discurso nem as entidades do mundo têm uma segmentação já pronta, dada $a$ priori; os referentes, ou objetos de discurso, são categorias cognitivo-discursivas e apresentam uma instabilidade inerente a eles". (CAVALCANTE, 2011, p. 26). Tal instabilidade refere-se às variadas possibilidades de (re)construção de um referente, o qual não corresponde a uma realidade objetiva, mas a uma construção linguístico-discursiva que é concretizada em função dos propósitos do falante

\footnotetext{
${ }^{13}$ Nesse excerto, os autores remetem aos próprios trabalhos que compõem a referida obra (cf. OAKLEY; HOUGAARD, 2008).

14 "Many cognitive linguists would perhaps consider this issue as being beyond the concerns of cognitive linguistics proper, as being a sociological not a cognitive or linguistics concern. But in truth cognitive linguistics in general and MSCI in particular are starting to address explicitly the issue of socially shared and constructed meaning”.
} 
(RODRIGUES, 2001). Os processos que constituem esse fenômeno ancoramse "no saber (partilhado) do destinador e do destinatário elaborado sobre a base do texto, do contexto e de conhecimentos socioculturais mais amplos [...]". (CAVALCANTE et al., 2010, p. 233).

Também é válido enfatizar a convergência entre Linguística do Texto e Linguística Cognitiva no que diz respeito à concepção de cognição corporificada e situada: perspectivas como a Hipótese Sociocognitiva da Linguagem (SALOMÃO, 1999) embasam os trabalhos que constituem esse campo na contemporaneidade. Dentre as diversas convergências explicitadas na literatura, destacamos a relevância de operações cognitivas amplamente exploradas no campo da LC para o processo de referenciação - por exemplo, linguistas do texto consideram que o processo de referenciação compreende alterações e manipulações de foco quanto ao objeto de discurso em jogo, realçando-se apenas as propriedades do referente que refletem o projeto de dizer do falante $(\mathrm{KOCH}, 2001)$.

Marcuschi (2003) vai ainda mais além quanto a essa interface, indicando que estruturas conceptuais, como a dos espaços mentais, constituem domínios implícitos, ativados por meio de inferência ao longo do processo de construção do objeto de discurso, em oposição a domínios explícitos, cuja formulação é completamente explicitada por meio da língua. Nessa perspectiva, retomando nosso exercício analítico, podemos dizer que o objeto de discurso Estados Unidos é construído inferencialmente por Chomsky, por meio da ativação de um espaço mental contrafactual.

Também é importante apontar que o campo da Linguística Textual se apropria claramente da noção de frame a partir dos autores que inspiraram a teoria fillmoriana ${ }^{13}$ (CAVALCANTE et al., 2010). Dentre eles, destacamos os trabalhos de Minsky - que, como referimos anteriormente, também inspiraram a abordagem contemporânea dos frames de compreensão, postulada por Ziem. Levando em conta essas aproximações, tencionamos relacionar brevemente, a seguir, o exercício analítico aos frames de compreensão e ao seu status de espaço de referenciação.

Se levarmos em conta a estrutura dos frames abordada na seção anterior, podemos considerar que os objetos de discurso terrorismo e Estados Unidos, nesse exemplo, sugerem uma contraposição com as estruturas de expectativa comumente veiculadas e partilhadas, nas quais Estados Unidos geralmente é o filler que instancia o slot [vítima] no frame Terrorismo. Consequentemente, o exemplo também sugere uma nova configuração para o frame Estados Unidos, "realçando e encobrindo" aspectos relativos à entidade, em consonância com a orientação

${ }^{15}$ Os autores afirmam que, ao buscar explicações que dessem conta de processos de inferência relativos à referenciação, a Linguística Textual recorreu a modelos "como a Teoria dos Esquemas (Rumelhart, 1975), a Teoria dos Frames (Minsky, 1976), a Teoria dos Scripts (Schank e Abelson, 1977), dentre outras." (CAVALCANTE, 2010, p. 231)

${ }^{16}$ Ressaltamos que essa ilustração se utiliza de apenas uma das abordagens de descrição e identificação de frames - pautada principalmente nas considerações de Ziem (2014), que se inspira nos trabalhos de Fillmore (1976; 1982; 1985). 
argumentativa da frase - para Ziem (2014), essas múltiplas possibilidades de ativação de slots do frame é que constituem seu espaço de referenciação. Complementando esse aspecto, consideramos que, ao sugerir trocas e refutações de slots e fillers ${ }^{15}$ no processo de construção dos referentes Estados Unidos e Terrorismo, esse exemplo também ilustra a potencialidade analítica da dimensão online do frame. (VEREZA, 2013a).

Ao encontro dessa possibilidade, acreditamos ser imperioso articular a postulação desse espaço sociocognitivo de referenciação à deliberalidade explicitada pelos estudiosos da Linguística do Texto. Como pontua Koch (2002, p. 31),

\footnotetext{
A referenciação constitui, assim, uma atividade discursiva. O sujeito, na interação, opera sobre o material linguístico que tem à sua disposição, operando escolhas significativas para representar estados de coisas, com vistas à concretização do seu projeto de dizer (Koch, 1999; 2002). Isto é, os processos de referenciação são escolhas do sujeito em função de um querer dizer.
}

Dessa forma, consideramos o enfoque proposto pela Linguística do Texto é convidativo a propostas interdisciplinares que visem a explorar a complexidade do processo sociocognitivo de referência/referenciação, principalmente quanto a sua faceta ideológica e deliberativa.

Antes de procedermos às considerações finais, ressaltamos que o exercício analítico foi aqui realizado para fins de ilustração, sem demais pretensões teóricometodológicas. Além de termos nos valido de apenas um exemplo autêntico, sem ter realizado demais verificações para corroborar as considerações acerca das estruturas de expectativa mencionadas, é de se observar que a interface entre os planos estável e online nas abordagens cognitivo-discursivas, apesar de já apresentar avanços no que tange aos estudos sobre metáfora, ainda necessita avançar no que diz respeito à dimensão online dos frames. Nesse âmbito, conforme buscamos indicar em nossas reflexões, a proposição de novas ferramentas teórico-analíticas que considerem essa interface pode ser extremamente profícua para o estudo da referência como fenômeno multifacetado e ancorado sociocognitivamente.

\section{CONSIDERAÇÕES FINAIS}

Neste ensaio, objetivamos tratar da referência no contexto da Linguística Cognitiva, situando, primeiramente, o empreendimento a partir das concepções de referência advindas da tradição filosófica. Dessa forma, na primeira parte, abordamos as perspectivas predominantemente logicistas e binárias da referência na tradição filosófica ocidental, com a qual contrapomos o realismo corpóreo postulado por Lakoff e Johnson (1999). Em termos epistemológicos, a partir dessas considerações, acreditamos que o fenômeno da referência nos permite

\footnotetext{
17 "Uncharted territory".
} 
compreender a significativa mudança paradigmática postulada pelos pressupostos filosóficos de Lakoff e Johnson (1999) em relação à filosofia analítica tradicional.

O segundo propósito residiu na abordagem das estruturas conceptuais lócus da referência nessa corrente, incluindo as estruturas locais ou online. Assim, levando em conta a primazia do sistema conceptual na Linguística Cognitiva, na segunda parte, buscamos mostrar a relação intrínseca entre estruturas conceptuais e referência, preconizando a necessidade de convergência entre abordagens cognitivo-discursivas para um tratamento mais abrangente desse processo. Nesse contexto, destacamos os processos deliberativos e ideológicos inerentes a esse fenômeno, focando nas contribuições que a Linguística do Texto tem oferecido por meio do estudo da referenciação, e buscamos propor um olhar convergente que perspectivizasse uma construção online de frames.

Assim, em complementação à visão de Ziem quanto a essas estruturas, diríamos que, na esteira de uma busca por modelos multidisciplinares e considerando o paradigma textual-discursivo da referência, é necessário reconhecer que o frame somente se constitui como espaço de referenciação em virtude de estratégias empregadas pelos falantes em prol de uma construção de mundo que está a serviço de seus fins discursivos. Como enfatiza Koch (2009, p. 31), "a realidade é construída, mantida e alterada não somente pela forma como nomeamos o mundo, mas, acima de tudo, pela forma como, sociocognitivamente, interagimos com ele: interpretamos e construímos nossos mundos por meio da interação com o entorno físico, social e cultural." (grifo nosso).

Ainda quanto à valorização de perspectivas interdisciplinares com vistas ao estudo da referência como processo sociocognitivo-discursivo, importa salientar que não defendemos, de forma alguma, a combinação descriteriosa de abordagens distintas a fim de cumprir com uma agenda interdisciplinar para dar conta do fenômeno - muito menos a desvalorização de postulados linguístico-cognitivos no estudo da referência -, dado que o papel das estruturas de expectativa nesses processos, conforme abordamos neste ensaio, é fundamental. Nesse sentido, acreditamos que Moura, Vereza e Espíndola (2013, p. 191) sintetizam muito bem essa questão ao pontuarem que

[...] uma análise que se limite ao nível textual e discursivo, mesmo que revele toda a riqueza da argumentação textualmente desenvolvida, dos processos de referenciação e da construção do objeto de discurso, irá deixar de buscar as instâncias cognitivas mais estáveis, como as metáforas conceptuais, modelos cognitivos idealizados (MCIs- LAKOFF, 1987) ou frames, que subjazem ao que parece, em um primeiro olhar não informado, totalmente inédito.

Dito isso, reiteramos os desafios de pesquisa que essas propostas convergentes podem impor, dada a necessidade de proposição de novos métodos, modelos de análise e formas de perspectivizar os respectivos objetos de investigação. Tendo em vista a considerável dimensão desse "território inexplorado"17 (KOLLER, 2014, p. 242), reiteramos aqui o convite de Segundo (2014, p. 47) a tal desbravamento multidisciplinar: "Os caminhos estão abertos; falta apenas trilhá-los." 


\section{REFERÊNCIAS BIBLIOGRÁFICAS}

ARAÚJO, I. L. Do signo ao discurso: introdução à filosofia da linguagem. São Paulo: Parábola Editorial, 2004.

CAMERON, L.; MASLEN, R. (Org.) Metaphor analysis: research practice in applied linguistics, social sciences and the humanities. London: Equinox, 2010.

CAVALCANTE, M. et al. Dimensões textuais nas perspectivas sociocognitiva e interacional. In: BENTES, A. C.; LEITE, M. Q. (Orgs.). Linguística de texto e análise da conversação: panorama de pesquisas no Brasil. São Paulo: Cortez. 2010. p. 171-224.

CAVALCANTE, M. Referenciação: sobre coisas ditas e não ditas. Fortaleza: UFC, 2011.

CHOMSKY, N. US, A Leading Terrorist State in the World: Chomsky. Mountain View: Google, 2013. (26 min 12 s). Disponível em: $<$ https://www.youtube.com/watch? $\mathrm{v}=\mathrm{J}$ YRtZZ $-7 \mathrm{w}>$. Acesso em: 27 fev. 2017.

CIENKI, A. Frames, Idealized Cognitive Models, and Domains. In: GEERAERDTS, D.; CUYCKENS, H. (Orgs.) The Oxford Handbook of Cognitive Linguistics. New York: Oxford University Press. 2017. p. 48-81.

DIRVEN, A.; POLZENHAGEN, F.; WOLF, H.-G. Cognitive Linguistics, Ideology and Critical Discourse Analysis. In: GEERAERDTS, D.; CUYCKENS, H. (Orgs.) The Oxford Handbook of Cognitive Linguistics. New York: Oxford University Press. 2017, p. 1222-1240.

FAUCONNIER, G. Mental Spaces. Cambridge: MIT Press, 1985.

FAUCONNIER, G. Mappings in Thought and Language. Cambridge University Press, 1997.

FAUCONNIER, G. Mental spaces. Cambridge: Cambridge University Press, 1994.

FAUCONNIER, G.; TURNER, M. The Way We Think: Conceptual Blending and The Mind's Hidden Complexities. Nova York: Basic Books, 2003.

FILLMORE, C. J. Frame semantics and the nature of language. In: Annals of the New York Academy of Sciences: Conference on the Origin and Development of Language and Speech, [S.1.], v. 280, 1976, p. 20-32.

FILLMORE, C. J. Scenes-and-frames semantics. In: ZAMPOLLI, A. (Ed.): Linguistic structures processing: fundamental studies in computer science, n. 59, North Holland Publishing. 1977. p. 55-88.

FILLMORE, C. J. Frame Semantics. In: Linguistics in the Morning Calm. Seoul, Hansinh Publishing Co., 1982.

FILLMORE, C. J. Frames and the semantics of understanding. In: Quaderni di Semantica, vol. 6, n. 2, 1985. p.222-254.

FREGE, G. On Sense and Reference. In: GEACH, P.; BLACK, M. (Eds.). Translations from the Writings of Gottlob Frege. 2ed., 56-78. Oxford: Blackwell, 1960. 
HART, C. Discourse. In: DABROWSKA, E.; DIVJEK, D. (Eds.) Handbook of Cognitive Linguistics. Berlin: Mouton De Gruyter. 2015, p. 322-346.

KOCH, I. V.; MARCUSHI, L. A. Processos de referenciação na produção discursiva. DELTA, São Paulo, v. 14, número especial, 1998. Disponível em: $<$ http://www.scielo.br/scielo.php?script=sci artte xt\&pid=S010244501998000300012\&lng=en\&nrm=iso $>$. Acesso em: 30 mar. 2017.

KOCH, I. V. A referenciação como atividade cognitivo-discursiva e interacional. Cadernos de Estudos Linguísticos, v. 41, n. 75, 2001, p. 75-89, jul.-dez. Disponível em: $<$ http://revistas.iel.unicamp. br/index.php/cel/article/view/1775> . Acesso em: 09 mar. 2017.

KOCH, I. V. Linguagem e cognição: a construção e reconstrução de objetos-de-discurso. Veredas, Juiz de Fora, v. 6, n. 1, 2002, p. 29-42. Disponível em: <http://www.ufjf.br/revistaveredas/ files/2009/12/cap022.pdf $>$. Acesso em: 03 mar. 2017.

KOLLER, V. Cognitive Linguistics and Ideology. In: LITTLEMORE, J.; TAYLOR, J. (Orgs.) The Bloomsbury companion to Cognitive Linguistics. London/New York: Bloomsbury. 2014, p. $1-23$.

LAKOFF, G. Women, Fire, and Dangerous Things. Londres: The University of Chicago, 1990.

LAKOFF, G.; JOHNSON, M. Philosophy in the Flesh. New York: Basic Books, 1999.

LAKOFF, G.; JOHNSON, M. Metaphors we live by. London: The University of Chicago Press, 2003.

LANGACKER, R. W. Foundations of cognitive grammar: theoretical prerequisites. Stanford: Stanford University Press, 1987.

MARCONDES, D. Filosofia Analítica. Rio de Janeiro: Jorge Zahar Editor, 2004.

MARCUSCHI, L. A. Atos de referenciação na interação face a face. Cadernos de Estudos Linguísticos, v. 41,2001, p. $37-54$.

MARCUSCHI, L. A. Atividades de referenciação, inferenciação e categorização na produção de sentido. In: FELTES, H. M. P. (Org.) Produção de sentido: estudos transdisciplinares. São Paulo: Ana Blume; Porto Alegre: Nova Prova; Caxias do Sul: EDUCS, 2003.

MINSKY, M. A framework for representing knowledge. In: Artificial Intelligence Memo, n. 306. Cambridge, MA: Massachusetts Institute of Technology, 1974.

MIRANDA, N. S. Domínios conceptuais e projeções entre domínios: uma introdução ao Modelo dos Espaços Mentais. Veredas: revista de estudos linguísticos, Juiz de Fora, v. 3, n. 1, p. 81-95, 1999.

MONDADA, L.; DUBOIS, D. Construção dos objetos e categorização: uma abordagem dos processos de referenciação. In CALVACANTE, M. M.; RODRIGUES, B. B.; CIULlA, A. (Org.). Referenciação. São Paulo: Contexto. 2003, p. 17-52.

MOURA, H.; VEREZA, S.; ESPÍNDOLA, L. Metáfora e contexto: entre o estável e o instável. Interdisciplinar: Edição Especial ABRALIN/SE, Itabaiana/SE, Ano VIII, v.17, 2013, jan./jun.

OAKLEY, T.; HOUGAARD, A. Mental spaces in discourse and interaction. Amsterdam/Philadelphia: John Benjamins, 2008. 
RODRIGUES, A. D. A partitura invisivel: para uma abordagem interactiva da linguagem. Lisboa: Edições Colibri, 2001.

ROSCH, E. Natural categories. In: Cognitive Psychology, [S.1.], v. 4, n. 3, 1973, p. 328-350.

RUSSELL, B. Da denotação. (Coleção Os Pensadores, v. Russell). São Paulo: Abril, 1989 [1918].

SALOMÃO, M. M. A questão da construção de sentidos e a revisão da agenda dos estudos da linguagem. Veredas, Juiz de Fora, v. 3, n. 1, 1999, p. 61-79.

SALOMÃO, M. Razão, Realismo e Verdade: o que nos ensina o estudo sociocognitivo de referência. Caderno de Estudos Linguísticos, vol. 44, 2003, p. 71-84.

SEGUNDO, P. R. G. Convergências entre a Análise Crítica do Discurso e a Linguística Cognitiva: integração conceptual, metáfora e dinâmica de forças. Veredas, Juiz de Fora, v. 18, n. 2, 2014, p. 32-50. Disponível em: <http://www.ufjf.br/revistaveredas/files/2015/04/3-SEGUNDO1.pdf>. Acesso em: 24 mar. 2017.

SEMINO, E. Metaphor in discourse. Cambridge: Cambridge University Press, 2008.

SILVA, D. F. Pensar e argumentar: a linguagem do adolescente. São Leopoldo: Unisinos, 1998.

TANNEN, D. What's in a Frame? Surface Evidence for Underlying Expectations. In: FREEDLE, R. (Ed.) New Directions in Discourse Processing. Norwood: Ablex, 1979.

TANNEN, D.; WALLAT, C. Interactive Frames and Knowledge Schemas in Interaction: Examples from a Medical Examination/Interview. In: Tannen, D. Framing in Discourse. New York: Oxford University Press, 1987.

VEREZA, S. O lócus da metáfora: linguagem, pensamento e discurso. Cadernos de Letras da UFF_Dossiê: Letras e cognição n. 41, 2010, p. 199-212.

VEREZA, S. Entrelaçando frames: a construção do sentido metafórico na linguagem em uso. Cadernos de Estudos Linguísticos, Campinas, v. 55, n. 1, jan./jun, 2013 a.

VEREZA, S. "Metáfora é que nem...”: cognição e discurso na metáfora situada. Signo, Santa Cruz do Sul, v. 38, n. 65 , p. 2-21, jul. dez, 2013 b.

VEREZA, S. Mal comparando...: os efeitos argumentativos da metáfora e da analogia numa perspectiva cognitivo-discursiva. SCRIPTA, Belo Horizonte, v. 20, n. 40, p. 18-35, 2. sem., 2016.

WITtGensteIN, L. Investigações Filosóficas. (Coleção Os Pensadores, v. Wittgenstein). São Paulo: Abril, 1980 [1953].

WITTGENSTEIN, L. Tractatus Logico-Philosophicus. São Paulo: EDUSP, 1993 [1921].

ZIEM, A. Frames of understanding in text and discourse. Amsterdam: John Benjamins, 2014.

Recebido: 06/03/2017

Aceito: 11/04/2017 